\title{
Recent Developments in Sputter-Deposited Ti-Ni-Base Shape Memory Alloy Thin Films
}

\author{
S. Miyazaki, K. Nomura, A. Ishida* and S. Kajiwara* \\ Institute of Materials Science, University of Tsukuba, Tsukuba, Ibaraki 305, Japan \\ * National Research Institute for Metals, 1-2-1 Sengen, Tsukuba, Ibaraki 305, Japan
}

\begin{abstract}
Since 1992 the present authors have been successful in making Ti-Ni shape memory alloy thin films, which can show perfect shape memory effect and superelasticity equivalent to those of bulk materials; by utilizing a r.f. sputtering method. In the present paper, some of their recent results were reviewed. The alloys investigated are $\mathrm{Ti}-\mathrm{Ni}$, $\mathrm{Ti}-\mathrm{Ni}-\mathrm{Cu}$ and $\mathrm{Ti}-\mathrm{Ni}-\mathrm{Pd}$, the alloy content ranging from 45.4 to 51.9 at $\% \mathrm{Ni}$ for $\mathrm{Ti}-\mathrm{Ni}$, from 0 to 18.0 at $\% \mathrm{Cu}$ for $\mathrm{Ti}-\mathrm{Ni}$ $\mathrm{Cu}$ and from 0 to 21.8 at\% Pd for Ti-Ni-Pd. The Ti-Ni films were used for investigating the effects of Ni-content and heat-treatment condition on the transformation and deformation behavior, the effect of cyclic deformation on the stability of shape memory behavior, the effect of nonequilibrium state created during crystallization process on the transformation behavior, etc. The Ti-Ni-Cu films were made in order to decrease the transformation hysteresis, while the Ti-Ni-Pd films were made in order to increase the transformation temperatures: both are effective to increase the response speed in actuation.
\end{abstract}

\section{INTRODUCTION}

Among several types of functional materials proposed for microactuators, Ti-Ni shape memory alloy has been considered to be an attractive and promising material, because it has large recovery strain and driving force: besides, even it's intrinsic disadvantage such as a slow response due to the limitation of cooling rate can be greatly improved in the form of thin film. Therefore, the development of sputter-deposited Ti-Ni thin films has been demanded since the early stage of the development of micromachines.

Since 1992 the present authors, using a thermomechanical testing, have been successful in characterizing a perfect shape memory effect associated with both the R-phase and martensitic transformations in sputterdeposited Ti-Ni thin films[1-7]. The shape change and recovery stress associated with the martensitic transformation in the Ti-Ni thin films reached up to $6 \%$ and 500MPa, respectively, which were equivalent to those of bulk specimens[8]. Since the sputter-deposited thin film has a thickness suitable for each application and it is neither necessary nor possible to cold-roll the film. The grain size of solution-treated Ti-Ni alloy thin films were determined by TEM to be submicron, much smaller than that of bulk specimens. The small grain size caused the resistance against slip deformation to increase. Even though the thin films can be cold-rolled, the advantage of batch processing in fabricating micromachines driven by sputter-deposited shape memory alloy thin film microactuators will be lost if the thin films are removed from the substrates.

It was also found that $\mathrm{Ti}-\mathrm{Ni}$ thin films show stable superelasticity when deformed at a temperature above Af [9-11]. Since the superelasticity is. accompanied by a stress hysteresis, it is necessary to apply a high enough stress to observe such superelasticity. In this case, the maximum stress applied to the film was higher than $600 \mathrm{MPa}$. This is also a good evidence showing that the sputter-deposited Ti-Ni thin films are stable. The shape memory behavior of the Ti-Ni thin films was also found to be enough stable against cyclic deformation in both cases of the R-phase and martensitic transformations [12,13].

Sputter-deposited thin films showed temperature dependence of shape memóry characteristics even in $\mathrm{Ni}$-poor content films which do not show aging effect. This relates with nanometer scale substructures and nonequilibrium phase formed during recrystallization and following annealing process [14]. These nanometer scale substructures are effective in increasing the shape memory characteristics by increasing the critical stress for slip. In case of $\mathrm{Ni}$-rich Ti-Ni thin films, of course, aging effect is available for stabilizing shape memory behavior, and systematic investigation has been done to show how aging temperature and time affect the size and density of Ti3Ni4 precipitates and shape memory characteristics [15,16].

The R(Rhombohedral)-phase transformation was also observed in the Ti-Ni thin films $[16,17]$. The shape change associated with the R-phase transformation is only one-tenth as large as that associated with the martensitic transformation. Therefore, the cyclic characteristics of shape memory behavior associated with the R-phase transformation are quite stable [12]. Another characteristic of the R-phase transformation is a small temperature hysteresis of about several Kelvin, resulting in a quick response of shape memory behavior in the $\mathrm{Ti}-\mathrm{Ni}$ thin films. 
Ti-Ni-Cu and Ti-Ni-Pd ternary shape memory alloy thin films were also made by sputtering[18-21]. They showed smaller temperature hystereses and higher transformation temperatures, respectively, than those of Ti-Ni binary thin films; these characteristics are effective to achieve a high response actuator characteristics. The transformation temperatures and shape memory behavior were characterized by DSC measurement and tensile tests, respectively. The Ti-Ni thin films showed a single stage or two stage transformation associated with the monoclinic martensite (M-phase) and/or the R-phase. However, the ternary alloy thin films showed another type of two-stage transformation; the first stage corresponds to the transformation between $\mathrm{B} 2$ and $\mathrm{O}$ (Orthorhombic)-phase and the second stage between the $\mathrm{O}$ - and M-phases. The first stage transformation was accompanied by a small temperature hysteresis. All these ternary thin films also showed perfect shape memory effect.

In the present paper, some of the above recent results obtained by the present authors will be reviewed.

\section{EXPERIMENTAL}

Ti-Ni, Ti-Ni-Cu and Ti-Ni-Pd shape memory alloy thin films were made by a r.f. magnetron sputtering method using a Ti-50.0at\% Ni target with the diameter of 4 inches. The films were deposited on glass or $\mathrm{Cu}$ substrates. Different alloy compositions were prepared by changing number of small $\mathrm{Ti}, \mathrm{Cu}$ and $\mathrm{Pd}$ plates put on the Ti-Ni target. The compositions of the films were determined by the electron probe X-ray microanalysis (EPMA). The alloy compositions of the films thus analyzed range from $43.9 \mathrm{at} \% \mathrm{Ni}$ to 51.9 at $\% \mathrm{Ni}$ for $\mathrm{Ti}-\mathrm{Ni}$, from $\mathrm{Oat} \% \mathrm{Cu}$ to 18 at $\% \mathrm{Cu}$ for $\mathrm{Ti}-\mathrm{Ni}-\mathrm{Cu}$ and from 0 at\% $\mathrm{Pd}$ to $22 \mathrm{at} \% \mathrm{Pd}$ for $\mathrm{Ti}-\mathrm{Ni}-\mathrm{Pd}$, respectively. After removing these thin films from the substrates, they were cut into three shapes of specimens, i.e., $3 \times 3 \mathrm{~mm}^{2}$ for DSC (differential scanning calorimetry), $1 \times 5 \mathrm{~mm}^{2}$ (gauge portion) for mechanical tests and $7 \times 17 \mathrm{~mm}^{2}$ for X-ray diffractometry, the film thickness being around $7 \mu \mathrm{m}$; then they were annealed at $973 \mathrm{~K}$ for $3.6 \mathrm{ks}$. After the annealing, some films were age-treated at various temperatures ranging from $573 \mathrm{~K}$ to $773 \mathrm{~K}$ for various time ranging from zero to $360 \mathrm{ks}$.

Crystal structures of the films were determined by $\mathrm{X}$-ray diffractometry, using $\mathrm{Cu}$ - $\mathrm{K} \alpha$ radiation. In order to investigate the crystal structural change as a function of temperature, the films were set on a stage which can vary the temperature of the films between $123 \mathrm{~K}$ and $343 \mathrm{~K}$. Transformation temperatures were determined by DSC. Shape memory behavior was characterized by measuring the strain induced in the film during cooling and heating under a variety of constant applied stresses. Superelastic behavior was investigated by tensile tests at fixed temperatures.

\section{RESULTS AND DISCUSSION}

\subsection{Crystal structures}

Figure 1 shows the $\mathrm{X}$-ray diffraction profiles showing three crystal structures measured at 320,270 and $200 \mathrm{~K}$, respectively, in the Ti-51.9at\% Ni alloy thin film which was agetreated at $773 \mathrm{~K}$ for $36 \mathrm{ks}$. The parent (B2) phase, R-phase and martensitic (M)phase exist independently at these temperatures, respectively. The lattice constants of each phase are shown on the right side of the corresponding diffraction pattern. These lattice constants of the three phases are essentially the same as those measured in bulk Ti-Ni alloys, although they vary only slightly depending on the alloy content.

Similar measurements were made in $\mathrm{Ti}-\mathrm{Ni}-\mathrm{Cu}$ and $\mathrm{Ti}-$ $\mathrm{Ni}-\mathrm{Pd}$ alloy thin films. The lattice constants of the parent B2 phase and monoclinic phase were determined in Ti41.0Ni-7.9Cu(at\%) as follows: $\mathrm{a}_{0}=0.3032 \mathrm{~nm}$ for the former, $a=0.2858 \mathrm{~nm}, b=0.4189 \mathrm{~nm}, c=0.4551 \mathrm{~nm}$ and $\beta=96.50 \mathrm{de}-$ grees for the latter, while the lattice constants of the orthorhombic phase were determined to be $a=0.2912 \mathrm{~nm}$, $b=0.4229 \mathrm{~nm}, c=0.4540 \mathrm{~nm}$ and $\beta=90.00$ degrees. Two stage transformation was also observed in a $\mathrm{Ti}-37.7 \mathrm{Ni}$ $8.8 \mathrm{Pd}(\mathrm{at} \%)$ film. The lattice constants were $\mathrm{a}_{0}=0.3042 \mathrm{~nm}$ for the parent B2 phase, $a=0.2850 \mathrm{~nm}, b=0.4291 \mathrm{~nm}$, $c=0.4612 \mathrm{~nm}$ and $\beta=90.00$ degrees for the orthorhombic phase, and $a=0.2866 \mathrm{~nm}, b=0.4163 \mathrm{~nm}, c=0.4657 \mathrm{~nm}$ and $\beta=96.76$ degrees for the monoclinic phase.

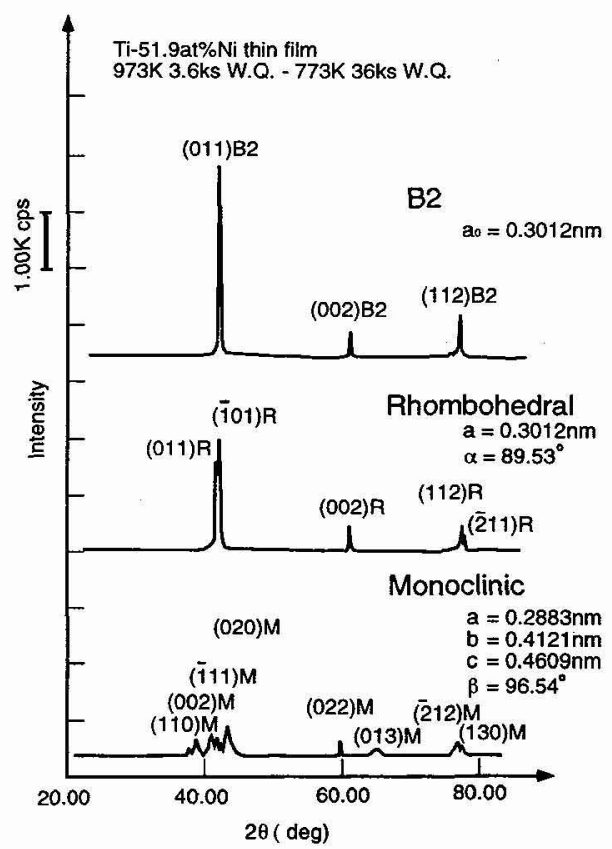

Figure 1: X-ray diffraction profiles of the parent $\mathrm{B} 2, \mathrm{R}$-phase and monoclonic martensite phase in Ti-51.9 at\% Ni thin films. 


\subsection{Effect of heat-treatment on the transformation and deformation behavior in Ti-Ni thin films}

Figure 2 shows the effect of aging time on the transformation temperatures of the Ti-51.9at\%Ni alloy thin films which were aged at $773 \mathrm{~K}$ for $\mathrm{X} \mathrm{ks}$ after solution treatment at $973 \mathrm{~K}$ for $3.6 \mathrm{ks}$. The solid lines show the DSC curves measured upon cooling, while the dashed curves those upon heating. Solution treated film $(\mathrm{X}=0)$ shows no transformation peak upon cooling on the DSC curve, indicating that the transformation temperatures are very low, hence again no reverse transformation peak upon heating. In age-treated thin films, there are two transformation peaks appearing on each solid curve; the two peaks correspond to the Rphase and martensitic transformations whose peak temperatures are denoted by $R^{*}$ and $M^{*}$, respectively. Upon heating the age-treated films show only one reverse transformation peak $A^{*}$ except for the film aged for $3.6 \mathrm{ks}$ which shows two transformation peaks $A^{*}$ and $R A^{*}$. The $A^{*}$ points of the films aged for 36 and $360 \mathrm{ks}$ represent the reverse transformation from $\mathrm{M}$ directly to $\mathrm{B} 2$, while $A^{*}$ and $R A^{*}$ of the film aged for $3.6 \mathrm{ks}$ represent the reverse transformations from $\mathrm{M}$ to $\mathrm{R}$ and from $\mathrm{R}$ to $\mathrm{B} 2$, respectively. Both of the $R^{*}$ and $M^{*}$ show an aging effect which causes them to increase with increasing aging time. However, $M^{*}$ increases more sensitively to the aging time than $R^{*}$. The increase in $M^{*}$ and $R^{*}$ can be mainly explained by the decrease in the Ni-content of the matrix of the film, because the growth of the $\mathrm{Ti}_{3} \mathrm{Ni}_{4}$ precipitates will consume excess $\mathrm{Ni}$ in the matrix and the transformation temperatures increase with decreasing $\mathrm{Ni}$-content of the matrix.

The shape memory behavior of the thin films used in Fig. 2 is shown in Fig. 3. Strains were measured upon cooling (solid lines) and heating (dashed lines) under $240 \mathrm{MPa}$. Two-stage shape change appears both at $R s$ and $M s$ in the age-treated thin films, while a single stage shape change at $M s$ in the thin film without aging. All the Rs and $M s$ in Fig. 3 are higher than those estimated by the DSC curves, because the DSC curves were measured under no load, while the strain was measured under stress: the stress increases the transformation temperatures following the Clausius-Clapeyron relationship. Since $M s$ (or $M^{*}$ ) increases more effectively by aging than $R s$ (or $R^{*}$ ), the temperature difference between $R s$ and $M s$ becomes smaller with increasing aging time. On the other hand, the strain induced by the martensitic transformation increases with increasing aging time, indicating that as the Ti3Ni4 precipitates grow by aging they will lose the suppressing force against the growth of the preferentially oriented martensite variants.

The aging effect was also investigated in the $\mathrm{Ti}-43.9 \mathrm{at} \% \mathrm{Ni}$ thin film. There is no aging effect observed in the transformation and deformation behavior in this $\mathrm{Ni}$-poor $\mathrm{Ti}-\mathrm{Ni}$ thin film.

The data of the aging effect on the $M s$ of both the Ti-51.9at\% Ni and Ti-43.9at\% Ni thin films are shown by plotting the $M s$ against aging time in Fig. 4, where $M s$ temperatures measured by both the DSC and mechanical tests (MEC) are shown. Controlling transformation temperatures is one of the necessary techniques in order to fabricate shape memory alloy thin film microactuators suitable for various purposes. The $M s$ increases with increasing aging time in the Ti-51.9at\% Ni, while it does not show any aging effect in the

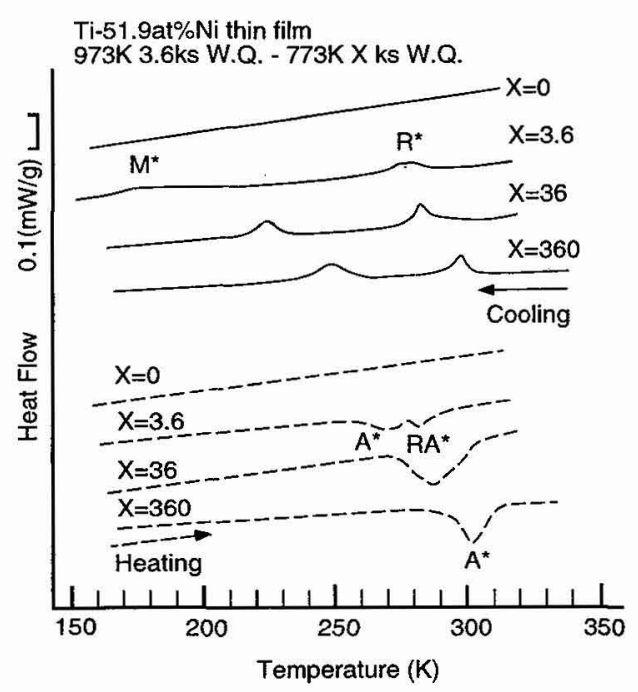

Figure 2: Effect of aging time on the transformation temperatures measured by DSC in the Ti-51.9at\% Ni thin film.
Ti-51.9at\%Ni thin film

973K 3.6ks W.Q. - 773K X ks W.Q.

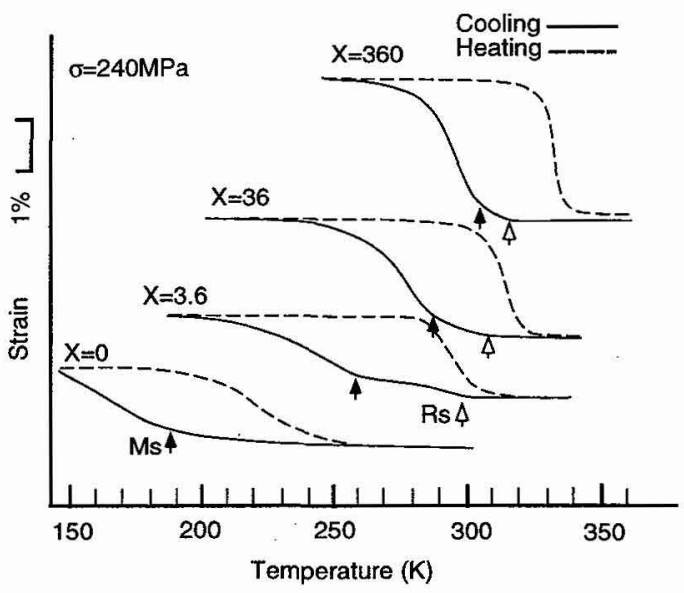

Figure 3: Effect of aging time on the shape memory behavior in the Ti-51.9at\% Ni thin film. 
Ti-43.9at\%Ni film. These alloys are considered to possess different advantageous characteristics for fabricating microactuators: i.e., the former Ni-rich alloy shows the aging effect so that the transformation temperatures are adjustable by heat-treatment even if the alloy content of the film can not be adjusted as one wishes, while the latter $\mathrm{Ni}$-poor alloy does not show the aging effect so that the transformation temperatures are not sensitive to the variation of heat treatment condition.

As shown in the above, Ni-poor Ti-Ni thin films will not show aging effect. However, they show annealing temperature dependence of the shape memory characteristics. Figure 5(a) shows such a result obtained in the Ti48.2at\% Ni thin film which was annealed at various temperatures. The critical stress for slip deformation $\left(\sigma_{s}\right)$ is plotted as a function of annealing temperature. The stress decreases with increasing annealing temperature until about $850 \mathrm{~K}$, then becomes almost constant. The strengthening effect observed in the lower annealing temperature region originates from the internal structure including nonequilibrium nanometer scale thin plate precipitates along $\{100\}$ planes. The composition of these thin plate precipitates is T-rich and they do not exist if annealed at a higher annealing temperature region, where the internal structure of the thin film only consists of Ti2Ni particles which are of equilibrium phase. The maximum shape recovery strain in Fig. 5(b) shows a similar annealing temperature dependence as $\sigma s$, except in the lower temperature region, where the strain increases with increasing annealing temperature. This is attributable to the fact that the thin film was not perfectly crystallized.

\subsection{Stability of shape memory characteristics against cyclic deformation}

\subsubsection{R-phase transformation}

Figure 6 shows the effect of cyclic deformation under $100 \mathrm{MPa}$ on the shape memory behavior associated with the R-phase transformation in an age-treated Ni-rich Ti$\mathrm{Ni}$ thin film. The solid lines represent strain-temperature curves upon cooling and the dotted lines those upon heating. The method how to evaluate the shape memory characteristics is illustrated in the first cycle $(\mathrm{N}=1)$ curve of Fig. 6(a). Each of the age-treated thin films shows a small temperature hysteresis $(H R)$ of less than $10 \mathrm{~K}$ and perfect shape recovery. It is also found that no significant change occurs in the shape of the curves in each specimen during the first 100 cyclings. The reason for the stability can be explained by the fact that the R-phase transformation strain is so small that slip deformation hardly occurs.

\subsubsection{M-phase transformation}

Figure 7 shows the same type of results as Figure 6 for the shape memory behavior associated with both the martensitic and R-phase transformations in the same specimen under 250MPa. Although the total transformation strain

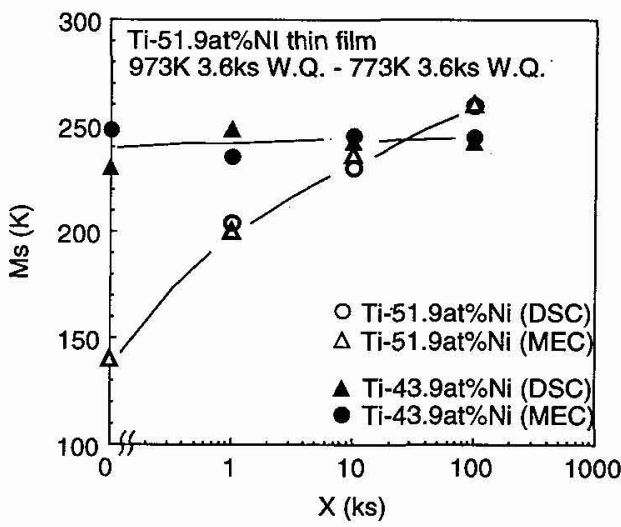

Figure 4: Effect of aging time on the martensitic transformation start temperature $M s$ in the Ti-51.9 at $\% \mathrm{Ni}$ and $\mathrm{Ti}-43.9$ at $\% \mathrm{Ni}$ thin films.
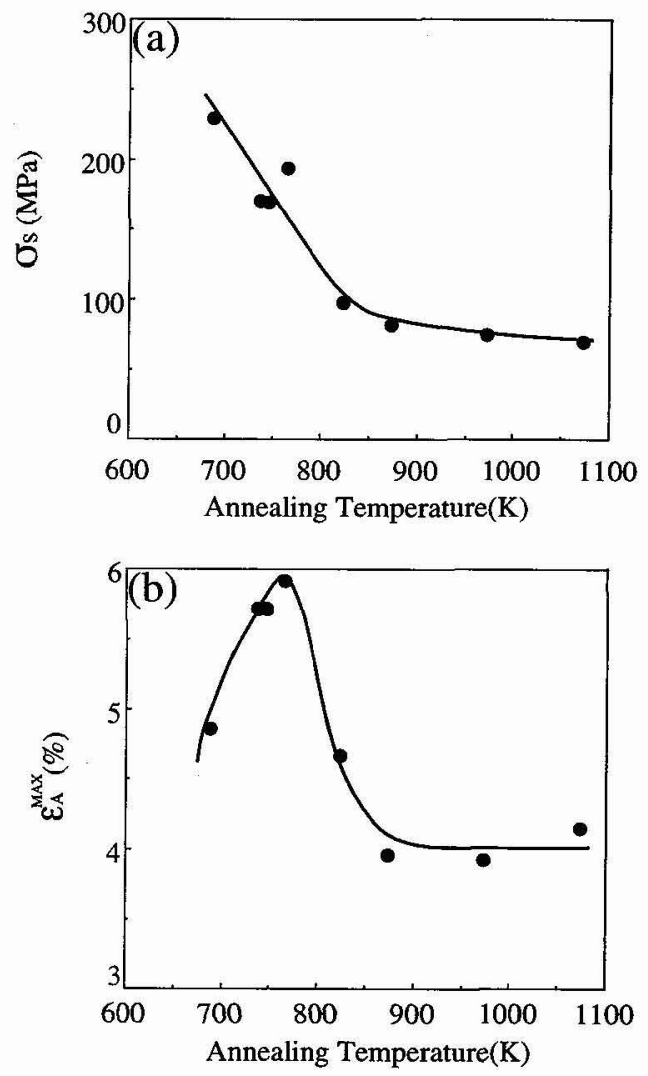

Figure 5: Annealing temperature dependence of (a) critical stress for slip and (b) the maximum recovery strain in Ti-48.2at\% Ni thin films.

is ten times larger than that of the R-phase transformation, the shape memory behavior shows a small change only in the first ten cycles and then becomes stable. Since the stability of the shape memory behavior originates from work hardening, it can be expected to continue after 100 cycles. 


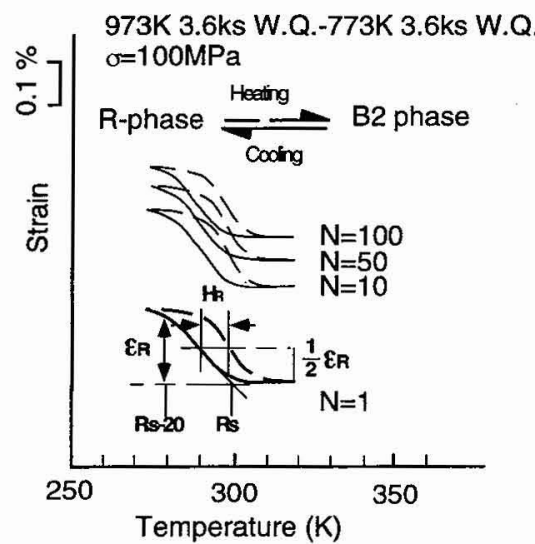

Figure 6: Effect of cyclic deformation under $100 \mathrm{MPa}$ on the strain-temperature curve associated with the R-phase transformation in age-treated Ti-50.5at\% $\mathrm{Ni}$ thin film. $\mathrm{N}$ indicates the number of thermal cycles.

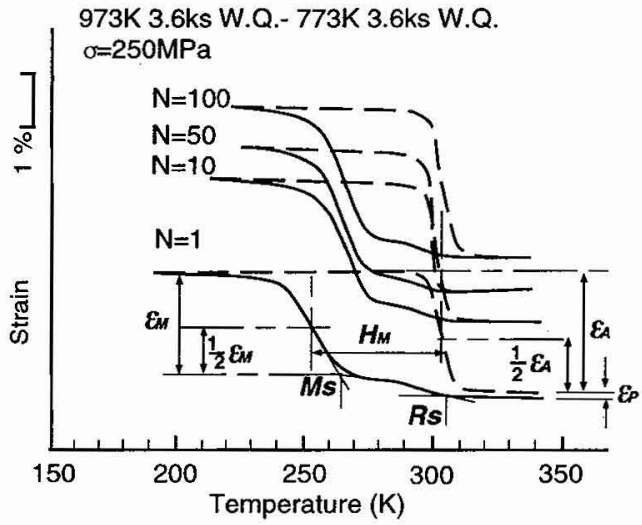

Figure 7: Effect of cyclic deformation under $250 \mathrm{MPa}$ on the strain-temperature curve associated with the martensitic transformation in age-treated Ti-50.5at\% $\mathrm{Ni}$ thin film. $\mathrm{N}$ indicates the number of thermal cycles.

\subsection{Small transformation temperature hysteresis in $\mathrm{Ti}$ - $\mathrm{Ni}-\mathrm{Cu}$ thin films}

Figure 8 shows the transformation temperatures of the Ti$\mathrm{Ni}-\mathrm{Cu}$ thin films measured by DSC as a function of $\mathrm{Cu}-$ content, Ti-content being kept around 51at\%. Two types of transformations occur in association with the monoclinic (M) phase transformation and the orthorhombic $(\mathrm{O})$ phase transformation. $M^{*}$ and $O^{*}$ are the transformation peak temperatures of the $\mathrm{B} 2 \leftrightarrow \mathrm{M}$ (or $\mathrm{O} \leftrightarrow \mathrm{M})$ and $\mathrm{B} 2 \leftrightarrow \mathrm{O}$, respectively, while $A^{*}$ and $O A^{*}$ the transformation peak temperatures of the corresponding reverse transformations, respectively. They are as high as those of bulk specimens, implying that the thin films contain few impurities. The $M^{*}$ decreases slightly with increasing $\mathrm{Cu}$-content until 9.5 at\%. The 9.5 at $\% \mathrm{Cu}$ alloy shows a two-stage transformation, the first transformation temperature $O^{*}$ being $314 \mathrm{~K}$ and the second one $M^{*}$ being $270 \mathrm{~K}$. By further increasing $\mathrm{Cu}$-content, $M^{*}$ decreases drastically, while $O^{*}$ increases slightly.

The temperature hysteresis $\left(A^{*}-M^{*}\right)$ or $\left(O A^{*}-O^{*}\right)$, shows a strong $\mathrm{Cu}$-content dependence as shown in Fig. 9. Stronger $\mathrm{Cu}$-dependence is observed in a single stage transformation region than in a two-stage transformation region. The hysteresis decreases from $27 \mathrm{~K}$ to $11 \mathrm{~K}$ with increasing $\mathrm{Cu}$-content from $0 \mathrm{at} \%$ to $9.5 \mathrm{at} \%$, and these properties are comparable to those of bulk specimens. Perfect shape memory effect was also observed in all the Ti$\mathrm{Ni}-\mathrm{Cu}$ thin films, revealing the small transformation temperature hysteresis behavior.

\subsection{High transformation temperatures in Ti-Ni-Pd thin films}

Figure 10 shows the effect of Pd-content on the transformation temperatures $(M s, O s, R s)$ in Ti-Ni-Pd thin films which were annealed at $973 \mathrm{~K}$ for $3.6 \mathrm{ks}$, Ti-content being kept from 50.0 to $51.0 \mathrm{at} \%$. Ms decreases slightly with

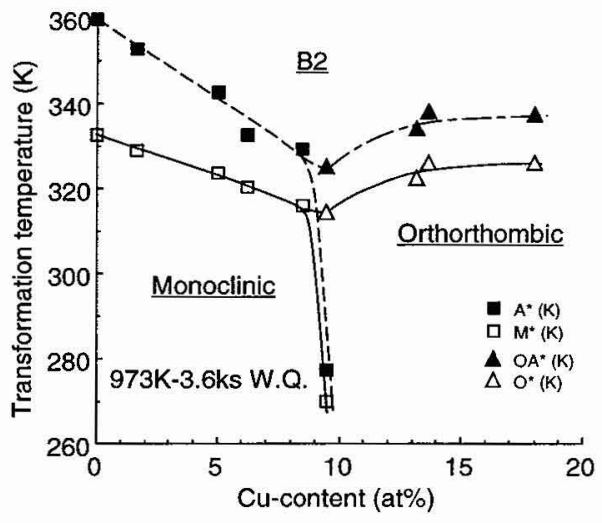

Figure 8: $\mathrm{Cu}$-content dependence of transformation temperature $\left(\mathrm{A}^{*}, \mathrm{M}^{*}\right.$, $\left.\mathrm{OA}^{*}, \mathrm{O}^{*}\right)$ in $\mathrm{Ti}-\mathrm{Ni}-\mathrm{Cu}$ thin films.

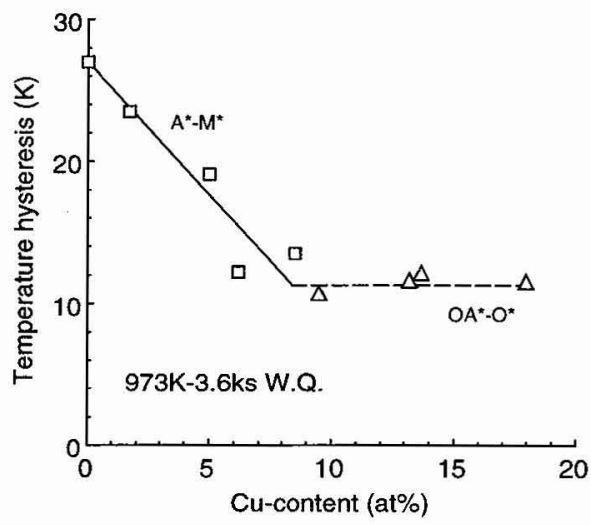

Figure 9: Effect of $\mathrm{Cu}$-content on the transformation temperature hysteresis in Ti-Ni-Cu alloy thin films. 




Figure 10: Pd-content dependence of transformation start temperatures (Ms, Rs and Os) in Ti-Ni-Pd thin films.

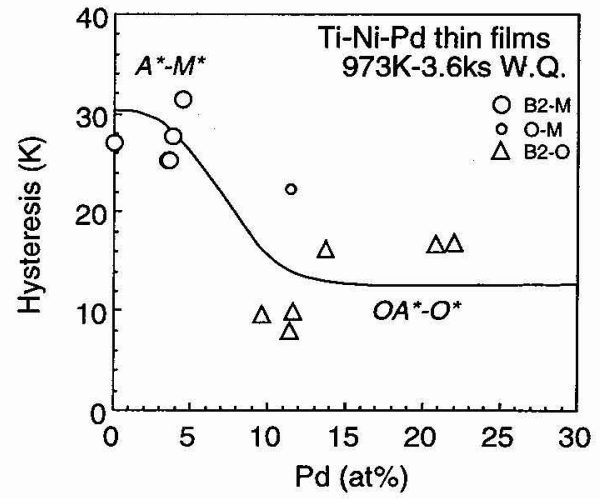

Figure 11: Effect of Pd-content on the temperature hystereses $\left(\mathrm{A}^{*}-\mathrm{M}^{*}, \mathrm{OA}^{*}-\mathrm{O}^{*}\right)$ in Ti-Ni-Pd thin films.

increasing Pd-content until around $6 \mathrm{at} \%$, then increases up to $390 \mathrm{~K}$, which is $54 \mathrm{~K}$ higher than that of the binary $\mathrm{Ti}-\mathrm{Ni}$ film. On the other hand, the transformation temperature hysteresis is also strongly affected by Pd-content, i.e., it decreases with increasing Pd-content down to around $10 \mathrm{~K}$ as shown in Fig. 11. This is an unexpected phenomenon, but both the Pd-content effects are useful in achieving quick response in actuation.

\section{CONCLUSIONS}

Ti-Ni binary alloy thin films with a Ni-content ranging from 43.9 at $\%$ to 51.9 at\%, Ti-Ni-Cu ternary alloy thin films with a Ti-content of about 51 at $\%$ and a Cu-content ranging from 0 at $\%$ to 18 at $\%$, and $\mathrm{Ti}-\mathrm{Ni}-\mathrm{Pd}$ ternary alloy thin films with a Ti-content kept from 50at\% to 51 at $\%$ and a Pd-content ranging from 0at\% to 22 at $\%$ were made by r.f. sputtering. They were solution-treated at $973 \mathrm{~K}$, and some of the binary alloys were age-treated at $773 \mathrm{~K}$ for various times ranging from zero to $360 \mathrm{ks}$ after the solution treatment. Their transformation and deformation behavior was characterized by X-ray diffractometry, DSC and tensile tests. All these thin films showed a perfect shape memory effect and typical effects of heat treatment and alloy content which are similar to those observed in bulk specimens. Therefore, sputter-deposited Ti-Ni-base thin films are really applicable as microactuators for driving micromachines.

\section{References}

[1] Miyazaki S., Ishida A. and Takei A., Proc. Intern.Symp.on Measurement and Control in Robotics, Tsukuba(1992)pp.495-500.

[2] Ishida, A., Takei, A. and Miyazaki, S., Thin Solid Films, 228 (1993) 210-214.

[3] Miyazaki S. and Nomura K., Proc. MEMS-94, Oiso, Japan, (1994) pp.176-181.

[4] Miyazaki S. and Ishida A., Materials Transactions, JIM, 35 (1994) 14-19.

[5] Ishida, A., Takei, A. and Miyazaki, S., Thin Solid Films, 228 (1993) 210-214.

[6] Miyazaki, S. and Ishida, A., Materials Transactions, JIM, 35 (1994) 14-19.

[7] Ishida A., Sato M., Takei A. and Miyazaki S., Materials Trans., JIM, 36 (1995) 1349-1355.

[8] Miyazaki, S., Ohmi, Y., Otsuka, K. and Suzuki, Y., Journal de Physique, 43, C4 (1982) pp.255-260.

[9] Miyazaki, S., Nomura K. and He Z., Proc. SMST-94, Pacific Grove, California, (1994) pp.19-24.

[10] Ishida A., Takei A., Sato M. and Miyazaki S., Thin Solid Films, 281-282 (1996) 337-339.

[11] Grummon D.S., Hou L., Zhao Z. and Pence T.J., Journal de Physique IV, C8, 5 (1995) pp.665-670.

[12] Nomura K. and Miyazaki S., Smart Materials, SPIE Proc. Series, 2441 (1995) pp.149-155.

[13] Nomura K., Miyazaki S. and Ishida A., Journal de Physique IV, 5, C8 (1995) pp.695-700.

[14] Kajiwara S., Kikuchi T., Ogawa K., Matsunaga T. and Miyazaki S., Phil. Mag. Letters, 74 (1996) 137-144, $395-404$.

[15] Ishida A., Sato M., Takei A., Nomura K. and Miyazaki S., Metall. and Maters. Trans. A, 27A (1996) 3753-3759.

[16] Miyazaki S., Nomura K. and Ishida A., Journal de Physique IV, C8, 5 (1995) pp.677-682.

[17] Miyazaki S., Kurooka S. and Hoshiya T., Trans. Mat. Res. Jpn., 18B (1994) 1045-1048.

[18] Miyazaki S., Hashinaga T., Yumikura K., Horikawa H., Ueki T. and Ishida A., ibid. [12], pp.95-103.

[19] Hashinaga T., Miyazaki S., Ueki T. and Horikawa H., Journal de Physique IV, 5 (1995) pp.689-694.

[20] Miyazaki S., Hashinaga, T. and Ishida A., Thin Solid Films, 281-282 (1996) 364-367.

[21] Quant E., Halene C., Holleck H., Feit K., Kohl M., Schloßmacher P., Skokan A. Skrobanek K.D., Sensors and Actuators A, 53 (1996) 434-439. 